\title{
¿Quién consiguió más liderazgo de opinión en la consagración de la Sagrada Familia, el Papa o el Templo?
}

\author{
Enric ORDEIX Rigó \\ Universitat Ramon Llull \\ eordeix@gmail.com \\ Ferrán LALUEZA BosCH \\ Universitat Oberta de Catalunya \\ flalueza@uoc.edu
}

Recibido: 04/10/2012

Aceptado: 16/01/2013

\begin{abstract}
Resumen
La consagración del Templo Expiatorio de la Sagrada Familia en Barcelona por parte de Benedicto XVI, el 7 de noviembre de 2010, marcó un debate público y mediático sobre su conveniencia por su coste y logística. Esta investigación es un análisis para conocer las razones y argumentos de noticiabilidad de los contenidos aparecidos en las principales medios de comunicación escritos catalanes, españoles e internacionales. El liderazgo de opinión, la representatividad, el debate mediático y la legitimidad asociada a la identidad y los valores, son temáticas de reflexión que consideramos clave para justificar la disparidad de criterios en el trato de la información referente a la consagración del templo publicada por parte de los principales rotativos el día después.
\end{abstract}

Palabras clave: Simbolismo, liderazgo de opinión, relaciones públicas, legitimidad, noticiabilidad.

\section{Who got more opinion leadership during the consecration of La Sagrada} Família, the Pope or the Temple?

\begin{abstract}
The consecration of the Cathedral of La Sagrada Familia in Barcelona by Benedict XVI on November 7, 2010, marked a public and media discussion about its suitability for their cost and logistics. This research is an analysis to ascertain the reasons and arguments of newsworthiness of the contents included in the major print Catalan, Spanish and international media. The opinion leadership, representation, the media debate and legitimacy associated with identity and values, are the key indicators to justify the disparity of views on the treatment of information concerning the consecration of the Cathedral, published by of the main media the day after.
\end{abstract}

Keywords: Simbolism, opinion lieadership, Public Relations, legitimacy, newsworthiness.

\section{Referencia normalizada}

ORDEIX RIGÓ, Enric y LALUEZA BOSCH, Ferrán (2013): “¿Quién consiguió más liderazgo de opinión en la consagración de la Sagrada Familia, el Papa o el Templo?". Estudios sobre el Mensaje Periodístico. Vol. 19, Núm. especial marzo, págs.: 351-359. Madrid, Servicio de Publicaciones de la Universidad Complutense.

Sumario: 1. Introducción del tema. 2. Fuentes y metodología. 3. Desarrollo. 4. Conclusiones. 5. Referencias bibliográficas

\section{Introducción del tema}

La ya evidente crisis, más la cuestionada legitimidad social del pontífice en algunos medios de comunicación españoles desdibujaban un posible éxito de convocatoria durante la visita. Sin embargo el peso social y expectativa generada por la inminente 
apertura al público del templo de la Sagrada Familia parecían poder paliar este problema. La simbología del Papa en el imaginario colectivo, como representante máximo del Vaticano, y la simbología de la Sagrada Familia, obra maestra de Gaudí construida a partir de donaciones de la sociedad civil, parecían complementarse en la lucha por conseguir un amplio espacio comunicativo ante los medios internacionales.

Todos los medios y la ciudadanía barcelonesa coincidieron, en cambio, en considerar que la consagración de la Sagrada Familia ofrecía mayor interés que los demás actos papales programados en la agenda de la visita. Así lo demuestran la presencia de cerca de 2.000 periodistas acreditados, la cobertura internacional de 150 millones de personas (el 66\% de share en Cataluña; récord de la cadena TV3 en esta franja horaria), las 50.000 personas que siguieron la ceremonia en el interior del templo y las 38.000 sillas ubicadas alrededor del mismo para permitir el seguimiento de la ceremonia a los que no tuvieron cabida dentro.

\section{Fuentes y metodología}

La metodología empleada parte de un estudio cualitativo de las noticias sobre la visita papal publicadas en los principales periódicos editados en Barcelona y Madrid (los que cuentan con un mínimo de 200.000 lectores de acuerdo con los datos del EGM/AIMC), así como en una muestra de las noticias publicadas por la prensa internacional de referencia, centradas en la visita del Papa a España. El corpus temporal establecido es el del día después de la visita, es decir, el 8 de noviembre de 2010.

Los medios analizados editados en Barcelona son La Vanguardia y El Períodico de Catalunya. Los medios analizados editados en Madrid son El País, El Mundo, Público, $A B C$ y La Razón. También se ha considerado la prensa gratuita en ambas ediciones (Madrid y Barcelona): 20 Minutos, ADN y QUÉ!. Y la muestra de prensa internacional analizada incluye: The New York Times (EEUU), Libération (Francia), The Independent (Reino Unido), La Reppublica (Italia), Corriere della Sera (Italia), Jurnal du Notícias (Portugal), Ultimas Noticias (Venezuela), El Universal (Venezuela) y El Comercio (Perú).

Los aspectos considerados en el análisis han sido:

a) La temática de la noticia y tema principal del titular

b) Los grupos clave identificados en el artículo

c) La adjetivación empleada

d) La maquetación de la noticia

En el análisis de estos aspectos, se han considerado también los indicadores siguientes:

1. Legitimidad

2. Representatividad

3. Simbolismo

4. Identidad y estética

5. Simbiosis social

6. Activismo público

7. Criterios de noticiabilidad 
La hipótesis planteada afirma que la figura de la Sagrada Familia ha prevalecido respecto a la figura del Papa en la cobertura mediática realizada por la prensa barcelonesa mientras que la figura de Benedicto XVI ha predominado respecto a la figura del templo en la prensa internacional y la editada en Madrid. Dicha hipótesis se sustenta de dos hechos clave: el carácter icónico y simbólico que tiene la Sagrada Familia para la ciudad de Barcelona y la implicación de la sociedad civil en su construcción (financiada exclusivamente a través de donaciones de particulares). Ambos hechos evidencian que el carácter civil de la noticia predomina sobre el religioso (Brown, 2003).

Respecto a las Fuentes los criterios de noticiabilidad, han sido identificados por varios autores como un factor que influye tanto en la agenda mediática como en la agenda pública (McComb, 1977). Es por ello que aquí se analiza la cobertura mediática obtenida por la visita papal a partir de los conceptos aportados en el ámbito de la agenda setting de los medios y de la agenda pública, de acuerdo con los principios básicos del story-telling y de la publicity. Por ejemplo, Yale (1991) destaca la necesidad de tener en cuenta el activismo público mientras que Henderson (2005) alude a los factores clásicos de proximidad, actualidad, preeminencia del sujeto y excepcionalidad. Todos ellos realzan la importancia del gatekeeper, el profesional que filtra los hechos y contribuye así a determinar qué es y qué no es noticia.

En términos de legitimidad y representatividad, las organizaciones intentan hallar un mínimo común denominador en las actitudes, apoyándose en los valores sociales y los símbolos para incrementar su presencia pública y su legitimidad. El papel de las relaciones públicas en este proceso de legitimación es demostrar la capacidad de la entidad para asumir tales principios (Ordeix y Duarte, 2009). De este modo, las relaciones públicas reformularon activamente la Sagrada Familia como símbolo que despierta el interés público, permitiendo así a las instituciones y a los grupos sociales implicarse en el proyecto. Se genera pues un movimiento de base que propicia la participación y el liderazgo de las instituciones públicas y los grupos sociales minoritarios, incluso al margen de la influencia de las instituciones religiosas (David, Kline y Dai, 2005). En este sentido, el amplio respaldo social con el que cuenta el templo ha condicionado la noticiabilidad que le otorgó la prensa barcelonesa.

Tal como establecen numerosos autores, el simbolismo y la estética tienen un papel de representación que incrementa, para el público, el grado de apoyo y legitimidad. De ahí que aquí hayan sido considerados elementos de análisis esenciales para entender el peso que tiene la Sagrada Familia en la cultura catalana. Sin embargo, la gran implicación de las instituciones locales, de los grupos sociales y religiosos, y de las entidades eclesiales catalanas y barcelonesas, no bastaron para influir en la cobertura de los medios internacionales y de los editados en Madrid tal como demuestran los resultados del análisis realizado. Las relaciones públicas podrían haberlo propiciado, de acuerdo con Heath y Coombs (2006) y Botam y Hazleton (2006). No obstante, la labor del departamento de relaciones públicas dedicado a la visita papal se centro más en la simbiosis social de la ciudadanía barcelonesa con el templo (asumido como símbolo de identidad social) que en el activismo con la prensa española e internacional (Payne, 2010); Szondi, G. (2008). 


\section{Desarrollo}

A su vez, el análisis de contenido realizado demuestra que, pese a la expectativa que se había creado en torno a la puesta de largo del templo de la Sagrada Familia, pese a la existencia de imágenes de esta nueva basílica dotadas de considerable espectacularidad y enorme impacto visual, y pese a que tales imágenes constituían una primicia mundial, es la figura del Sumo Pontífice la que protagoniza las portadas nacionales e internacionales del 8 de noviembre de los principales diarios. En la prensa editada en Madrid, de hecho, la obra de Gaudí es minimizada o incluso obviada de forma prácticamente unánime (Ordeix; Lalueza \& De Jaime, 2011).

Resulta paradigmático el caso del diario El Mundo, cuya portada ofrece la imagen del Papa en el Aeropuerto del Prat, pronunciando el discurso con el que cerró su visita a Barcelona ante la atenta mirada del presidente del Gobierno. En los elementos de titulación que contiene la información de portada, no aparece ni una sola referencia al templo de la Sagrada Familia. En cambio, en la edición del día anterior (7 de noviembre), el Pontífice es ubicado en la plaza del Obradorio tanto visualmente (por su vistosa capa de peregrino) como textualmente.

La misma foto difundida por El Mundo del discurso de despedida del Papa en el aeropuerto barcelonés (con Zapatero a la izquierda, a una distancia considerable que resalta el vacío que les separa) o una muy similar es la que protagoniza igualmente las portadas de El País y de Público. En el texto, se omite en ambos rotativos cualquier referencia a la basílica.

En el caso del diario $A B C$, la fotografía de portada muestra al Papa accediendo al templo por el pórtico de la Gloria. La porción de dicho pórtico visible en la imagen es tan de detalle, que el protagonismo del Pontífice resulta también en este caso indiscutible.

Aunque el titular principal alude a la familia, no es en referencia a la basílica sino al mensaje papal ("Por la vida y la familia"). De hecho, la denominación del tempo de Gaudí sólo aparece en el pie de foto y Barcelona no se menciona en absoluto. Curiosamente, en la edición de $A B C$ del día anterior ( 7 de noviembre), la localización del evento resulta mucho más explícita e incluso redundante tanto a nivel iconográfico (imagen del Papa con una gran cruz jacobea en la pechera de su capa de peregrino) como textual ("El primer peregrino" como título, "Los mensajes del Papa en Santiago de Compostela" como antetítulo y alusiones al "Camino" en uno de los cuatro subtítulos).

El análisis de las portadas de los diarios editados en Barcelona, en cambio, ofrece el enfoque opuesto. En La Vanguardia una imagen espectacular del interior del templo ocupa casi toda la portada (sólo queda la columna de la derecha para los elementos textuales). En la foto, la figura del Pontífice aparece minúscula en la parte inferior, apenas reconocible por la posición central que ocupa y por la mitra papal que cubre su testa. El Periódico de Catalunya sigue exactamente la misma pauta: foto del interior de la Sagrada Familia a toda plana. En esta última portada, la imagen del Pontífice también queda empequeñecida por la magnificencia del templo (aunque menos que en La Vanguardia). Esta excepcionalidad de la prensa editada en Barcelona se hace más evidente si cabe al comparar las ediciones de Barcelona y las de Madrid de los diarios gratuitos (ADN, QUÉ! y 20 Minutos). 
En el ámbito de la prensa internacional, la visita del Santo Padre a España fue reflejada de forma bastante diversa. Con todo, en general se destacaron las palabras del Pontífice respecto a los peligros del laicismo, su mensaje en favor del concepto tradicional de familia y, sobretodo las protestas del colectivo gay al paso de Benedicto XVI.

Algunos periódicos recogen en sus informaciones la dedicación de la Sagrada Familia de forma destacada, pero no ha sido este el eje central de las informaciones y no se han primado sus imágenes. El interés mediático generado por la espectacularidad o rareza de las fotos de la protesta superaron al del contenido y a las imágenes que se generaron en la basílica como resumen de una visita que tampoco generó una cobertura particularmente amplia.

Así, el periódico norteamericano The New York Times informó el día 7 de noviembre sobre la visita del Santo Padre a España, recogiendo en una fotografía un plano medio del pontífice circulando entre la gente y titulando "Visiting Spain, Pope sees rise of antichurch sentiment". Este periódico no recogió lo acontecido durante la jornada de domingo en Barcelona, si bien cabe señalar que el día 4 de noviembre se había publicado un artículo sobre la obra inacabada de Gaudí, mostrando una fotografía de archivo del templo, con el titular "Polishing Gaudi's unfinished jewel".

Uno de los pocos periódicos que informó en la dedicación del templo fue el diario francés Libération, que tituló el 8 de noviembre "Sagrada Familia: le pape consacre le rêve de Gaudi", y destacó en primer lugar que, 128 años después, la utopía de un arquitecto se hacía realidad.

En esta línea, informó también brevemente el periódico portugués Jornal du Notícias, que destacó en su titular la consagración del templo por parte de Benedicto XVI: "Papa/Espanha: Bento XVI consagra a Sagrada Família, a catedral do século XXI".

La mayor parte de la prensa internacional, no obstante, se centró en protesta realizada por un colectivo homosexual ante el paso del Papamóvil, consistente en besarse ante la presencia del Pontífice. Así, el periódico británico The Independent destaca en primer término sobre la visita de Benedicto XVI a España, la protesta realizada por dicho colectivo gay en Barcelona: "Pope's visit to Spain is met by gay kiss protest"

En la prensa italiana, el periódico La Reppublica, había publicado en su edición del 7 de noviembre un artículo sobre la llegada del pontífice a España, acompañado de una imagen de este descendiendo por la escalera del avión que lo trasladó a Santiago de Compostela. El artículo llevaba como titular "Benedetto XVI in visita in Spagna / Serve incontro fra fede e laicità". Pero, en su edición del día siguiente, el periódico no destacó la celebración de la Sagrada Família, sino la protesta del colectivo homosexual realizada ante el pontífice: "Il Papa in Spagna difende matrimonio / I gay lo accolgono con un bacio collettivo", ilustrando la noticia con una imagen de la protesta.

Otro periódico italiano, Corriere della sera, dedicó el 7 de noviembre un amplio artículo a la llegada del Santo Padre a España: "Fede e laicità si devono incontrare / Benedetto XVI in Spagna, dove consacrerà la Sagrada Familia: il dissidio tra arte e Chiesa fa male a entrambe". Se acompañó el texto de un primer plano del pontífice, y aparecen también varias fotografías de la recepción con los Príncipes. Pero de nuevo 
en la edición del día 8 de noviembre el periódico optó por destacar la protesta del colectivo gay. Así, el titular y las principales imágenes se centraron en este hecho: "La famiglia sia sostenuta dallo Stato", "Il Papa: «Servono adeguate misure economiche e sociali»" y "Ma prima c'era stata la protesta dei gay".

Los rotativos de América Latina recogieron también la visita del Santo Padre a España. Es el caso del venezolano Últimas Noticias, que resumió la visita con este titular: "El Papa les jaló las orejas a los españoles por su falta de religiosidad". Destacando el mensaje del pontífice pronunciado antes de aterrizar en Santiago de Compostela, El Universal (también venezolano) publicaba en la misma línea "El Papa critica con dureza el laicismo que existe en España" (Ordeix; Lalueza \& De Jaime, 2011).

Otros periódicos latinoamericanos profundizaron menos en el mensaje. Fue el caso de El Comercio, de Perú, que se limitó a señalar: "El Papa visita Barcelona".

\section{Conclusiones}

Si partimos de los principios de la estética y el simbolismo que rigen la visita del Papa, la Sagrada Familia tiene sin duda su propio carácter y valores como organización, hecho que podría haber obstaculizado la cobertura de los medios en relación al máximo representante de la Iglesia. Consejeros de prensa y departamentos de relaciones públicas del templo y de las instituciones civiles catalanas empujaron a medios de comunicación catalanes a considerar su información como prioritaria en la noticia de la visita. Esto daría lugar a la percepción de que los elementos de identidad de la Sagrada Familia, juntamente con valores representados por la conducta y apoyo social, civil, institucional, político y religioso (Toledano y Mckie, 2007), validarían la hipótesis de hacernos creer que la Sagrada Familia imperaría por encima de la figura del Papa, sus peculiaridades y características, y no al revés.

El indicador de representatividad y legitimidad, así como el de simbiosis social entre valores del templo y valores de la sociedad catalana, destacan en la mayoría de los periódicos de edición en Barcelona.

Visto desde esta perspectiva, constatamos que los medios de comunicación catalanes dieron preeminencia al principio de identidad y activismo público como argumento para publicar fotos que expresaban el gran apoyo social de la visita. En estos casos, las fotos y titulares hacían más hincapié en el templo expiatorio de la Sagrada Familia que en el pontífice. Fueron estos medios los que vivieron más intensamente la dualidad entre la Sagrada Familia y la figura del Papa y lo expresaron a través de los cuatro aspectos analizados en la noticia: el tema y protagonistas, los grupos clave, la adjetivación y la maquetación.

Así que, en términos de legitimidad (Ordeix y Duarte, 2009), no hay duda de que la iglesia consiguió por unos días ser un símbolo representativo de las instituciones catalanas, la sociedad civil y, obviamente, las organizaciones religiosas. Sin embargo, los resultados analizados en la prensa editada en Madrid demuestran que las referencias de los medios de comunicación refuerzan la figura del Papa, haciendo especial hincapié al mensaje Benedicto XVI y a su capacidad de convocatoria.

Desde la perspectiva de la noticiabilidad, y considerando como subelementos de análisis la proximidad, la preeminencia del personaje y la espectacularidad (Cobb y 
Elder, 1971; Heath, 2000), el significado y peso específico de la consagración del la Sagrada Familia no es el mismo ante los medios de comunicación internacionales, los de Madrid y los de Barcelona, debido a la variada aproximación de estos a temas de actualidad - de agenda mediática, política o pública- y a la fuerza de los activistas en contra o a favor de los postulados de Benedicto XVI. Consideramos, pues, que la presencia y el protagonismo del personaje principal, el Papa, es determinante por encima incluso del principio de la proximidad, conceptual y física, en que se rigen las noticias referentes a la Sagrada Familia, presentada a través de una estética e imágenes excepcionales.

Todavía, y referido a la noticiabilidad, creemos que las causas que pueden explicar que el templo de la Sagrada Familia obtuviera menos gramaje informativo que la figura de Benedicto XVI podrían ser varias:

- Primero, una mejor estrategia de relaciones públicas por parte del Vaticano en detrimento de la llevada a cabo por parte del arzobispado de Barcelona y la de los representantes del templo expiatorio, así como la proyección de los medios de comunicación que siguen habitualmente al pontífice.

- Segundo, el templo de la Sagrada Familia pasa a ser un mero escenario, singular y llamativo, para que el mundo conozca las ideas de Benedicto XVI y su mensaje persuasivo sea más eficaz, en línea con la preeminencia del carácter persuasivo de la comunicación (Lalueza, 2006).

- Tercero, es lógico afirmar, por tanto, que la capacidad persuasiva del Papa está fuertemente dominada por el discurso expresivo, que emana de una creación artística como la Sagrada Familia. Además, debemos considerar que la cobertura televisiva había revelado ya el día anterior la inusual imagen del templo, tomando la mayor parte del valor de la noticia y dejando el mensaje del Papa para los medios escritos. A su vez, el discurso del pontífice influye mejor en los periódicos que en las televisiones por su preeminencia textual, y por su mayor sorpresa informativa ante unas imágenes ya divulgadas con anterioridad por televisión.

- Por último, podemos añadir que los medios de comunicación escritos tienden a centrarse más en las personas que en las cosas, en línea con los argumentos que consideran el carisma como elemento determinante para la noticiabilidad de los hechos, tal y como indican Vercic y Vercic (2011).

Como reflexión final, podemos afirmar que, tal como se ha mencionado anteriormente, la lucha informativa generada entre las partes es evidente en los resultados expuestos, y que la disparidad de perspectivas por parte de la prensa editada en Madrid respecto a la de Barcelona queda claramente reflejada. La perspectiva también és diferente si comparamos ambos resultadoscon la muestra internacional de periódicos escogidos para la investigación. De todas formas, cabe mencionar que la prensa internacional va más alineada con la perspectiva que intensifica las palabras del pontífice (prensa editada en Madrid) y no tanto con la que subraya de antemano la información de la basílica por encima de la referente a Benedicto XVI (prensa editada en Barcelona). 
En la investigación se ha detectado que la lucha de símbolos y representatividad entre el Papa y la Sagrada Familia se debe muy probablemente a los diferentes valores, identidad y orígenes. Así que es lógico que los valores de referencia y de discusión provoquen perspectivas informativas diferentes en los varios medios de comunicación, según origen e intereses.

En definitiva, y por acabar, podemos reafirmar las palabras de G. Payne (2009) cuando constata que los procesos de búsqueda de la representación pública tiene lugar principalmente en los medios de comunicación como la nueva ágora política, y es el lugar donde la búsqueda de la legitimidad social (Ingenhoff y Furher, 2010) de las instituciones es más evidente.

\section{Referencias bibliográficas}

BOTAM, Carl. \& HAZLETON, Vincent (2006): Public Relations Theory. Mahwah, NJ, Lawrence Erlbaum.

BROWN, Robert E. (2003): "St. Paul As a Public Relations Practitioner: A Metatheoretical Speculation on Messianic Communication and Symmetry", en Public Relations Review, 29, 1-12.

COBB, Robert \& ELDER, Charles (1971): "The Politics of Agenda-Building: An Alternative Perspective for Modern Democratic Theory", en The Journal of Politics, 33, 892-915

DAVID, Prabu; KLINE, Susan \& DAI, Yang (2005): "Corporate Social Responsibility Practices, Corporate Identity and Purchase Intention: a Dual-process Model", en Journal of Public Relations Research, 17, 3, 291-313.

HEATH, Robert L. (2000): "A Rhetorical Perspective on the Values of Public Relations: Crossroads and Pathways Toward Concurrence", en Journal of Public Relations Research 12.1 (2000): 69-91. Disponible en: http://www.leaonline.com/doi /abs/10.1207/S1532754XJPRR1201_5?journalCode=jprr. [Fecha de consulta: 11 de marzo de 2012]

HEATH, Robert L., COOMBS, W. Timothy (2006): Today's Public Relations: An Introduction. Thousand Oaks, CA. Sage.

HENDERSON, David (2006): Making News: A Straight-shooting Guide to Media Relations. Lincoln, NE. Iuniverse.

INGENHOFF, Diana \& FUHRER, Tanja (2010): "Positioning and Differentiation by Using Brand Personality Attributes. Do Mission and Vision Statements Contribute to Building a Unique Corporate Identity? Corporate Communications", en An International Journal, 15,1, 83-101.

LALUEZA, Ferran (2006): "Does Persuasive Communication Constitute the Communicative Paradigm of the Knowledge Society?", en UOC Papers. Journal on Knowledge Society, 3 [en línea]. Disponible en: http://www.uoc.edu/uocpapers/3/dt/eng/lalueza.html. [Fecha de consulta: 15 de junio de 2012]

ORDEIX, Enric \& DUARTE, Joao (2009): "From Public Diplomacy to Corporate Diplomacy: Increasing Corporation's Legitimacy and Influence", en American Be- 
havioral Scientist, 53, 4, 549-564, doi:10.11770002764209347630; http://abs.sagepub.com. Thousand Oaks, CA, Sage.

ORDEIX, Enric; LALUEZA, Ferran \& DE JAIME, Sònia (2011): “Estudio de los criterios de noticiabilidad de la visita a Barcelona de Benedicto XVI. Análisis de caso", en Actas de la Revista Icono14 [en línea] no A6.pp. 538-549. Disponible en: http://www.icono14.net) [Fecha de consulta: 11 de marzo de 2012]

PAYNE, Gregory (2009): "President Barack Obama: Advocate of Grassroots Public Diplomacy", en Trípodos, 24, 1, 11-19.

SZONDI, Gyorgy (2008): "Public Diplomacy and Nation Branding: Conceptual Similarities and Differences. Discussion Papers in Diplomacy". Disponible en: http://www.clingendael.nl/publications/2008/20081022_pap_in_dip_nation_branding.pdf. [Fecha de consulta: 11 de marzo de 2012]

TOLEDANO, Margalit \& MCKIE, David (2007): "Social Integration and Public Relations: Global lessons from an Israeli Experience", en Public Relations Review, 37, 387-397.

VERČIČ, Ana Tkalac \& T.; VERČIČ, Dejan (2011): “Generic Charisma- Conceptualization and Measurement", en Public Relations Review Vol. 37 (1), 12-19.

YALE, David. (1991): The Publicity Handbook. Lincolnwood, CH. NTC.

\section{Enric ORDEIX RIGÓ}

Universidad Ramon Llull

Facultad de Comunicación y Relaciones Internacionales Blanquerna

Profesor investigador

eordeix@gmail.com

\section{Ferrán LALUEZA BOSCH}

Universitat Oberta de Catalunya

Doctor en Periodismo y profesor de Publicidad y Relaciones Públicas

flalueza@uoc.edu 